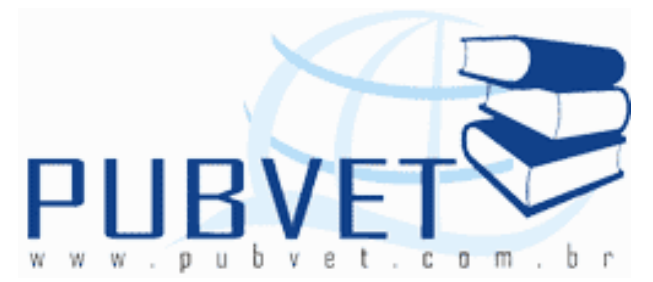

PUBVET, Publicações em Medicina Veterinária e Zootecnia.

\title{
Avaliação clínica do cloridrato de detomidina em ovinos
}

\author{
T. C. Trabach $^{1}$, R. J. S. Barros ${ }^{1}$, V. R. A. Mendes $^{1}$, M. A. Drago ${ }^{1}$, \\ P. M. C. Freitas' ${ }^{2}$, F. A. Lucas $^{3}$
}

${ }^{1}$ Aluno do Curso de Medicina Veterinária da Universidade Federal do Espírito Santo.

${ }^{2}$ Professora Adjunta do Curso de Medicina Veterinária da Universidade Federal de Minas Gerais

${ }^{3}$ Professora Adjunta do Curso de Medicina Veterinária da Universidade Federal do espírito Santo.

\section{Resumo}

Objetivou-se com este estudo relatar os efeitos clínicos do cloridrado de detomidina em ovinos, para a verificação de sua viabilidade nesta espécie. Foram utilizadas oito ovelhas, SRD, fêmeas, adultas, no período seco de lactação e hígidas, as quais receberam cloridrato de detomidina $(30 \mu \mathrm{g} / \mathrm{kg}$, IM). Avaliou-se anteriormente à administração deste fármaco e após seu uso, a cada 15 minutos, pelo período de 120 minutos, os parâmetros: frequências cardíaca (FC) e respiratória $(f)$, temperatura retal $\left(T^{\circ} \mathrm{C}\right)$, movimentos ruminais (MR), grau de sedação, postura e abaixamento da cabeça. O decúbito esternal foi observado em todos os animais após 15 minutos da administração de detomidina. Nos primeiros 15 minutos de observação verificou-se diminuições das FC, $f$ e da MR. Após este período, houve aumento gradativo da $\mathrm{FC}$, porém, 
TRABACH, T.C. et al. Avaliação clínica do cloridrato de detomidina em ovinos. PUBVET, Londrina, V. 5, N. 28, Ed. 175, Art. 1182, 2011.

permanecendo $33 \%$ abaixo dos valores basais aos 120 minutos. A $f$ e a MR retornaram aos valores basais no final do estudo. $A T^{\circ} \mathrm{C}$ diminuiu nos primeiros 75 minutos, voltando aos valores basais ao final do experimento. Nestas condições experimentais, pode-se concluir que a detomidina promove sedação em ovinos.

Palavras-chave: Agonistas alfa-2 adrenérgicos. Detomidina. Ovino. Sedação. Medicação pré-anestésica.

\section{Clinical evaluation of detomidine hydrochloride in sheep}

\section{Summary}

The purpose of this study was to describe the clinical effects of the use of detomidine hydrochloride in the ovine species. Eight sheep that were healthy, female gender and adults in the dry lactation period were used for this research. Detomidine hydrochloride was administered in the dose of $30 \mu \mathrm{g} / \mathrm{kg}$ IM. The following parameters: heart and respiratory rates, $\mathrm{T}^{\circ} \mathrm{C}$, ruminal movements, and evaluations of the degree of sedation, posture and lowering of the head; were measured before the administration of this drug, and after every 15 minutes until 120 minutes of observation were completed. Sternal decubitus was observed at 15 minutes after the administration of detomidine hydrochloride in all animals in this study. In the first 15 minutes, a decrease in heart and respiratory rates, and ruminal motility was noticed. After this period, a gradual increase in heart rate was detected, however persisting 33\% lower of basal values at 120 minutes of observation. The respiratory rate and ruminal motility returned to the basal values at the end of experimental period. The rectal temperature decreased in the first 75 minutes, returning to the basal values at the end of the study. In terms of this experimental study, the results indicates that detomidine hydrochloride promotes sedative effect in ovine, without causing significant adverse effects, recommended has a preanesthesic drug and tranquilizer in this species.

Keywords: Adrenergic alpha-Agonists, Detomidine, Ovine, Sedation. Preanesthetic Medication 
TRABACH, T.C. et al. Avaliação clínica do cloridrato de detomidina em ovinos. PUBVET, Londrina, V. 5, N. 28, Ed. 175, Art. 1182, 2011.

\section{INTRODUÇÃO}

Os agonistas a-2 adrenérgicos são fármacos utilizados para a produção de analgesia, sedação e miorrelaxamento em animais. O cloridrato de detomidina é comumente empregado em equinos, principalmente na pré-anestesia e como sedativo (SPINOSA \& GÓRNIAK, 2002). De acordo com Taylor \& Clarke (1999) e Khan (2003), este fármaco tem propriedades analgésicas e sedativas potentes, superior às promovidas pela xilazina nas espécies equina e bovina, sendo seu uso aprovado pelo Food and Drugs Administration (FDA) desde 1989.

Segundo Muir \& Hubbel (2001), a detomidina pode ser administrada por via intramuscular ou intravenosa, produzindo efeitos sedativo, relaxante muscular e analgésico, assim como pelas vias epidural ou subaracnoidea, para promover analgesia regional ou segmentária. É utilizada na medicação préanestésica, pois resulta em sedação dose-dependente (FANTONI \& CORTOPASSI, 2002).

Nos sistemas cardiovascular e respiratório, os agonistas a-2 causam hipertensão inicial seguida de hipotensão, bradicardia, redução do débito cardíaco e leve depressão respiratória (MUIR \& HUBBEL, 1991; SPINOSA \& GÓRNIAK, 2002; NATALINI, 2007). Aumento ou diminuição da motilidade do trato gastrointestinal também são observados após a administração desses fármacos. Em bovinos, diminuem prolongadamente a motilidade retículoruminal (ALMEIDA et al, 2005)e em equinos, é citada ainda a ocorrência de salivação, piloereção, transpiração, exposição peniana, tremor muscular discreto e abaixamento da cabeça (SPINOSA \& GÓRNIAK, 2002).

Poucos dados na literatura são encontrados sobre o uso do cloridrado de detomidina em ovinos, assim, objetivou-se verificar os efeitos clínicos deste fármaco, na dose de $30 \mu \mathrm{g} / \mathrm{kg}$ por via intramuscular, nesta espécie.

\section{MATERIAL E MÉTODOS}

Foram utilizadas oito ovelhas, adultas, hígidas e no período seco de lactação. O preparo dos animais envolveu jejum hídrico e alimentar de 12 e 24 
TRABACH, T.C. et al. Avaliação clínica do cloridrato de detomidina em ovinos. PUBVET, Londrina, V. 5, N. 28, Ed. 175, Art. 1182, 2011.

horas, respectivamente. No momento da administração do fármaco, cada animal foi mantido individualmente em local calmo e arejado.

Inicialmente, no momento denominado TO-A, foram aferidos os parâmetros fisiológicos frequência cardíaca ( $F C)$, frequência respiratória $(f)$, temperatura retal $\left(T^{\circ} \mathrm{C}\right)$ e movimentos ruminais (MR), e avaliados o grau de sedação, postura e abaixamento de cabeça. Decorridos 10 minutos (T0-B), foram feitas as mesmas aferições e avaliações, calculando-se, em seguida, a média entre T0-A e T0-B, obtendo-se, assim, o valor de T0. Após 10 minutos, os animais receberam, por via intramuscular, o cloridrato de detomidina na dose de $30 \mu \mathrm{g} / \mathrm{kg}$, diluída para o volume final de $0,5 \mathrm{~mL}$ com solução de cloreto de sódio a $0,9 \%$. Subsequente à administração da detomidina, os parâmetros descritos acima foram novamente aferidos a cada 15 minutos até que se completasse 120 minutos da administração do fármaco (T1, T2, T3, T4, T5, T6, T7 e T8). Atribuiu-se nesses momentos, para as variáveis sedação, postura e abaixamento de cabeça, valores de escore entre 0 e 5 , conforme representados no Quadro 1.

Os dados referentes às variáveis $\mathrm{FC}, f, \mathrm{~T}^{\circ} \mathrm{C}$ e $\mathrm{MR}$ foram tabelados $\mathrm{e}$ submetidos à análises do teste $t$ de Student para dados pareados, com nível de significância de $5 \%$. As avaliações estatísticas do grau de sedação, postura e abaixamento da cabeça foram analisados pelo teste de Wilcoxon para dados não paramétricos, com nível de significância de $5 \%$.

\section{RESULTADOS E DISCUSSÃO}

O cloridrato de detomidina promoveu sedação em todos os animais (Tabela 1). Após 15 minutos da administração ( $T 1$ ), os animais apresentaram decúbito esternal, mas ainda mantiveram a cabeça na posição normal. A partir de T2, 25\% dos animais apresentaram decúbito, porém, não conseguiram manter a cabeça erguida, apesar das constantes tentativas. 0 decúbito e o abaixamento da cabeça, observados em $100 \%$ e $25 \%$ dos animais, mantiveram-se até os 60 minutos (T4). Em T5, 50\% dos animais conseguiam se manter em estação, porém, com dificuldades de locomoção, 
TRABACH, T.C. et al. Avaliação clínica do cloridrato de detomidina em ovinos. PUBVET, Londrina, V. 5, N. 28, Ed. 175, Art. 1182, 2011.

ao passo que o restante das ovelhas continuaram em decúbito, mas com a cabeça em posição normal. No momento $\mathrm{T} 6,62,5 \%$ dos animais obtiveram posição quadrupedal, entretanto, 37,5\% ainda permaneceram em decúbito. Aos 105 minutos, 37,5\% dos animais estavam se locomovendo normalmente, $37,5 \%$ estavam andando com dificuldade e $25 \%$ permaneciam em decúbito. Ao final do período experimental (120 minutos), 100\% dos animais já estavam em estação, porém, 25\% ainda andavam com alguma dificuldade de locomoção. Não foram constatados, em nenhum momento, o decúbito lateral e ataxia. Assim, observou-se neste estudo, sedação e relaxamento muscular nos animais, concordando com o descrito por Fantoni \& Cortopassi (2002), as quais descreveram que a detomidina tem ação sedativa e miorrelaxante, mais evidenciada em algumas espécies, como nos ruminantes. Ademais, Khan (2003) relatou que, carneiros que receberam $50 \mu \mathrm{g} / \mathrm{kg}$ de detomidina pela via intramuscular, apresentaram sedação nos primeiros 15 minutos após a administração, que durou até os 120 minutos. Entretanto, os animais permaneceram em decúbito até os 105 minutos, resultado do relaxamento muscular provocado pela detomidina, o que não foi verificado neste estudo, no qual somente $25 \%$ dos animais permaneceram em decúbito após 105 minutos da injeção da detomidina. Isto provavelmente ocorreu devido à dose utilizada neste estudo, de $30 \mu \mathrm{g} / \mathrm{kg}$, via intramuscular, menor que a preconizada por Khan (2003). Em virtude do relaxamento muscular, Massone (2008) aconselha o jejum prévio e estendido por pelo menos duas horas, para evitar falsa via do alimento em decorrência do relaxamento da epiglote. Neste estudo não foi observada falsa via em nenhum momento, confirmando a importância do jejum prévio.

Fantoni \& Cortopassi (2002) relataram que, de modo geral, os animais apresentam certo grau de ataxia após receberem este agonista a-2 adrenérgico, o que não foi observado neste experimento. Além disso, o abaixamento da cabeça observado em algumas ovelhas condiz com o relatado por Fantoni et al. (1999) na espécie equina, todavia, apresentando-se menos evidente. 
TRABACH, T.C. et al. Avaliação clínica do cloridrato de detomidina em ovinos. PUBVET, Londrina, V. 5, N. 28, Ed. 175, Art. 1182, 2011.

Observou-se intensa bradicardia nos primeiros 15 minutos (Tabela 2) após a administração do cloridrato de detomidina (T1). Após este período, a FC elevou-se progressivamente até T8, no entanto, permanecendo 33,3\% abaixo do T0 (Figura 1) . A bradicardia foi decorrente do efeito dos agonistas a-2 adrenérgicos, os quais diminuem a FC nas espécies domésticas, em função da redução do tônus simpático e do aumento da atividade parassimpática (MUIR \& HUBBEL, 2001). Este achado concorda com Almeida et al. (2004), os quais relataram discreta bradicardia em vacas tratadas com xilazina por via epidural e comDória et al. (2009), que verificaram bradicardia em equinos submetidos à infusão contínua de medetomidina e de xilazina.

Com relação à $f$, notou-se diminuição significativa a partir de T2 até o momento final de aferição (Tabela 2), discordando do relatado por Bastos et al. (2005), que reportaram que a xilazina e a romifidina não produziram alterações relevantes neste parâmetro em cabras. Entretanto, nosso resultados corroboram o descrito por Fantoni et al. (1999), os quais evidenciaram diminuição deste parâmetro em equinos tratados tanto com a detomidina como com a romifidina por via intravenosa. A redução da $f$ observada neste estudo (Figura 2), confirma também o descrito por Fantoni \& Cortopassi (2002), as quais relataram que todos os agonistas a-2 causam depressão respiratória dependente da dose, com decréscimo da $f$.

A atividade ruminal foi inibida de maneira significativa a partir de T1, permanecendo desta forma até os 90 minutos de avaliação (Figura 3).Concordando com os achados de Elfenbein et al. (2009), os quais observaram diminuição da motilidade gastrintestinal em equinos após o uso de agonistas a-2. Segundo Almeida et al. (2005), os agonistas a-2 reduzem prolongadamente a motilidade retículo-ruminal em bovinos, por bloqueio do mecanismo adrenérgico central que coordena a motilidade dos pré-estômagos.

De acordo com Almeida et al. (2004), os agonistas a-2 aumentam, reduzem ou não interferem na temperatura retal de bovinos, porém, estes efeitos não foram explicados. Massone (2008) cita que, após a aplicação de agonistas a-2 em qualquer espécie, pode ocorre a elevação da temperatura em 
TRABACH, T.C. et al. Avaliação clínica do cloridrato de detomidina em ovinos. PUBVET, Londrina, V. 5, N. 28, Ed. 175, Art. 1182, 2011.

até $1^{\circ} \mathrm{C}$, voltando à normalidade em até 3 horas. No presente estudo, foi evidenciada a redução da $\mathrm{T}^{\circ} \mathrm{C}$ a partir de $\mathrm{T} 2$ até o final das aferições (Figura 4).

\section{CONCLUSÕES}

Nas condições deste estudo experimental, os resultados nos permitem concluir que a detomidina, quando aplicada por via intramuscular na dose de $30 \mu \mathrm{g} / \mathrm{kg}$, possui efeito sedativo em ovinos, apesar da ocorrência de bradicardia e hipomotilidade ruminal.

\section{REFERÊNCIAS}

ALMEIDA, R.M., VALADÃO, C.A.A, MORENO, J.C.D., FARIAS, A., SOUZA, A.H. Efeitos da administração epidural de amitraz, xilazina ou dimetil sulfóxido em vacas. Arquivo Brasileiro de Medicina Veterinária e Zootecnia, v. 56, n. 6, p. 723-732, 2004.

ALMEIDA, R.M., VALADÃO, C.A.A, MORENO, J.C.D., FARIAS, A., SOUZA, A.H. Avaliação dos efeitos do amitraz por via epidural em vacas. Brazilian Journal of Veterinary Research and Animal Science, v. 42, n. 6, p. 419-428, 2005.

BAGATINI, A., GOMES, C. R., MASELLA, M. Z., REZER, G. Dexmedetomidina: Farmacologia e Uso Clínico. Revista Brasileira de Anestesiologia, v. 52, n. 5, p.606- 617, 2002.

BASTOS, J.A.B.; PAES LEME, F.O.; ALVES G.E.S. Efeitos hemogasométricos da xilazina e da romifidina em cabras tratadas por ioimbina. Arquivos Brasileiro de Medicina Veterinária e Zootecnia,. v. 57, suppl. 2, p. 173-178, 2005.

DÓRIA, R.G.S., VALADÃO, C. A. A., CANOLA, P. A., ÉRICA CRISTINA BUENO DO PRADO GUIRRO, E. C. B. P. G., MENDES, M. C., ESCOBAR, A., RIBEIRO, G., NATALiNI, C. C. Anestesia por isofluorano em eqüinos submetidos à infusão contínua de medetomidina ou xilazina. Ciência Rural, v. 39, n. 2, p. 447-452, 2009.

ELFENBEIN, J. R., SANCHEZ, L. C., ROBERTSON, S.A., COLE, C.A., SAMS, R. Effect of detomidine on visceral and somatic nociception and duodenal motility in conscious adult horses. Veterinary Anaesthesia and Analgesia, v. 36, p. 162-172, 2009.

FANTONI, D.T., FUTEMA, F., CORTOPASSI, S. R. G., L. C. L. C. SILVA, VERENGUER, M., MIRANDOLA, R., FERREIRA, M. A. Avaliação comparativa entre acepromazina, detomidina e romifidina em eqüinos. Ciência Rural, v. 29, n. 1, p. 45-50, 1999.

FANTONI, D.T.; CORTOPASSI, S.R.G. Medicação pré-anestésica. In: Anestesia em Cães e Gatos. São Paulo: Roca, 2002, p. 151-158.

KHAN, M.A. Clinico-biochemical Studies on Detomidine Analgesia and Effects of its Combinations on Animals. Lahore: University of Veterinary and Animal Sciences, 2003. 287p. Tese (Doutorado) - Doctor of Philosophy in Veterinary Medicine. University of Veterinary and Animal Sciences. Lahore, 2003. 
MASSONE, F. Anestesiologia Veterinária: Farmacologia e Técnicas. 5.ed. Rio de Janeiro: Guanabara Koogan, 2008, 592p.

MUIR, W.W., HUBBEL, J.A.E. Medicação pré-anestésica. In: MUIR, W.W. et al. Manual de Anestesia Veterinária. 3.ed. Porto Alegre: Artmed Editora, 2001, p. 31-44.

MUIR, W.W. Standing chemical restraint in horses. In: MUIR. WW; HUBBEL, J.A.E. Equine anesthesia: monitoring and emergency therapy. St. Louis: Mosby, 1991, p. 247-281.

NATALINI, C.C. Medicação pré-anestésica. In:_Teoria e Técnicas em Anestesiologia Veterinária. Porto Alegre: Artmed, 2007, p. 43-66.

SPINOSA, H.S.; GÓRNIAK, S.L. Tranqüilizantes, relaxantes musculares de ação central e antidepressivos. In: SPINOSA, H.S.; GÓRNIAK, S.L.; BERNARDI, M.M. Farmacologia Aplicada à Medicina Veterinária. 3.ed. Rio de Janeiro: Guanabara Koogan, 2002, p. 146157.

TAYLOR, P.M.; CLARKE, K.W. Intravenous anaesthesia. In:

Anaesthesia. London: W. B. Saunders, 1999, p. 33-54. Handbook of Equine 
Quadro 1. Valores dos escores atribuídos aos parâmetros de sedação, postura e abaixamento da cabeça.

\begin{tabular}{|c|c|c|c|c|c|c|}
\hline & 0 & 1 & 2 & 3 & 4 & 5 \\
\hline Sedação & Acordado & $\begin{array}{c}\text { Anda com } \\
\text { dificuldade }\end{array}$ & $\begin{array}{c}\text { Tenta, mas não } \\
\text { fica em estação }\end{array}$ & $\begin{array}{c}\text { Em decúbito, mas } \\
\text { levanta a cabeça }\end{array}$ & $\begin{array}{c}\text { Tenta, mas não } \\
\text { levanta a cabeça }\end{array}$ & $\begin{array}{c}\text { Sem reação a } \\
\text { estímulos }\end{array}$ \\
\hline Postura & Quadrupedal & Sentado/atáxico & Decúbito esternal & Decúbito lateral & - & - \\
\hline $\begin{array}{c}\text { Abaixamento da } \\
\text { cabeça }\end{array}$ & Ausente & Presente & - & - & - & - \\
\hline
\end{tabular}

Tabela 1. Valores modais dos parâmetros de sedação, postura e abaixamento da cabeça em ovelhas $(n=8)$ após administração de $30 \mu \mathrm{g} / \mathrm{kg}$ de cloridrato de detomidina, de acordo com Quadro 1.

\begin{tabular}{|c|c|c|c|c|c|c|c|c|c|}
\hline & TO & $\overline{\mathbf{T 1}}$ & T2 & T3 & T4 & T5 & T6 & T7 & T8 \\
\hline Sedação & 0 & 3* & 3 & 3* & 3 & 3* & 1 & $1 / 0$ & $0 *$ \\
\hline Postura & 0 & $2 *$ & $2 *$ & $2 *$ & 2 & $0 *$ & 0 & 0 & $0 *$ \\
\hline $\begin{array}{l}\text { Abaixa } \\
\text { mento }\end{array}$ & 0 & 0 & 0 & $0 *$ & 0 & $0 *$ & $0 *$ & $0 *$ & $0 *$ \\
\hline de & & & & & & & & & \\
\hline cabeça & & & & & & & & & \\
\hline
\end{tabular}

\footnotetext{
* SIGNIFICATIVAMENTE DIFERENTE DO T ANTERIOR $(\mathrm{P} \leq 0,05)$
} 
Tabela 2. Valores médios e desvios padrão das variáveis fisiológicas em ovelhas $(n=8)$ após administração de $30 \mu \mathrm{g} / \mathrm{kg}$ de cloridrato de detomidina.

\begin{tabular}{llllllllll}
\hline & T0 & T1 & T2 & T3 & T4 & T5 & T6 & T7 & T8 \\
\hline FC & 97,8 & $56^{*}$ & $58,7^{*}$ & $60,7^{*}$ & $62,5^{*}$ & $62^{*}$ & $63,2^{*}$ & $63,5^{*}$ & $65,2^{*}$ \\
$(\mathbf{B P M})$ & {$[ \pm 17]$} & {$[ \pm 8]$} & {$[ \pm 8,6]$} & {$[ \pm 9,7]$} & {$[ \pm 7,7]$} & {$[ \pm 6,7]$} & {$[ \pm 9,5]$} & {$[ \pm 9]$} & {$[ \pm 12,7]$} \\
$\mathbf{f}$ & 44,6 & 39,7 & $30,2^{*}$ & $24,5^{*}$ & $23,5^{*}$ & $21,2^{*}$ & $20,7 *$ & $23^{*}$ & $22,7^{*}$ \\
$($ Mov/min) & {$[ \pm 18,1]$} & {$[ \pm 16,8]$} & {$[ \pm 8,7]$} & {$[ \pm 7,5]$} & {$[ \pm 4,7]$} & {$[ \pm 4,3]$} & {$[ \pm 4,1]$} & {$[ \pm 6,9]$} & {$[ \pm 10,5]$} \\
MR & 1,8 & $0,1^{*}$ & $0,1^{*}$ & $0,5^{*}$ & $0,5^{*}$ & $0,7^{*}$ & $1^{*}$ & 1,7 & 1,5 \\
$(\mathbf{M o v} / \mathbf{5 m i n})$ & {$[ \pm 0,5]$} & {$[ \pm 0,3]$} & {$[ \pm 0,3]$} & {$[ \pm 0,5]$} & {$[ \pm 0,5]$} & {$[ \pm 0,4]$} & {$[ \pm 0,7]$} & {$[ \pm 1]$} & {$[ \pm 0,9]$} \\
$\mathbf{T}^{\circ} \mathbf{C}$ & 39,7 & 39,6 & $39,3^{*}$ & $39,1^{*}$ & $38,9 *$ & $38,7 *$ & $38,8^{*}$ & $38,8^{*}$ & $38,9 *$ \\
$\left({ }^{\circ} \mathbf{C}\right)$ & {$[ \pm 0,6]$} & {$[ \pm 0,4]$} & {$[ \pm 0,5]$} & {$[ \pm 0,4]$} & {$[ \pm 0,4]$} & {$[ \pm 0,4]$} & {$[ \pm 0,4]$} & {$[ \pm 0,5]$} & {$[ \pm 0,7]$}
\end{tabular}

* SIGNIFICATIVAMENTE DIFERENTE DO TO $(\mathrm{P} \leq 0,05)$. 


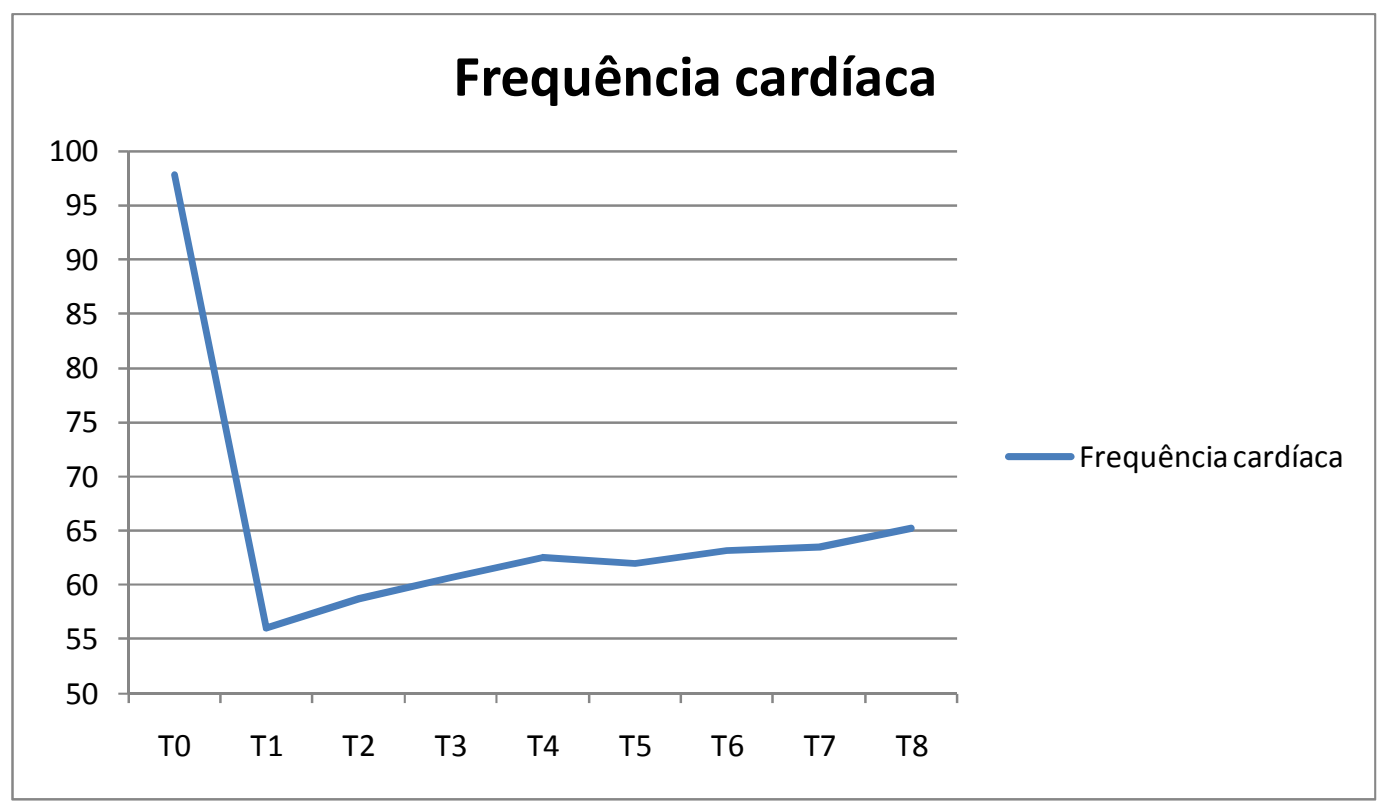

Figura 1 - Valores médios da frequência cardíaca (bpm) em ovelhas tratadas com $30 \mu \mathrm{g} / \mathrm{kg}$ de cloridrato de detomidina. 


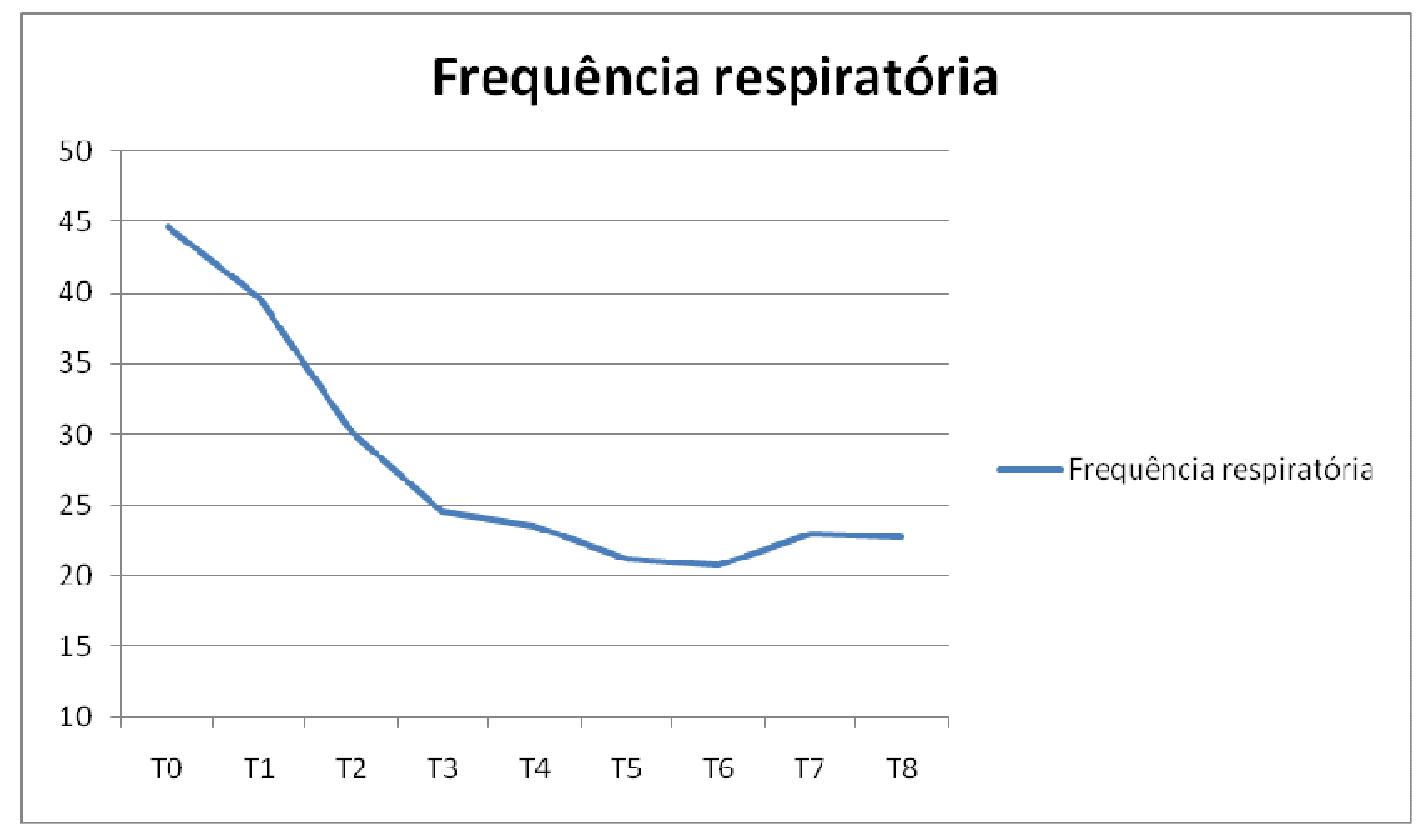

Figura 2 - Valores médios da frequência respiratória $(\mathrm{mpm})$ em ovelhas tratadas com $30 \mu \mathrm{g} / \mathrm{kg}$ de cloridrato de detomidina. 


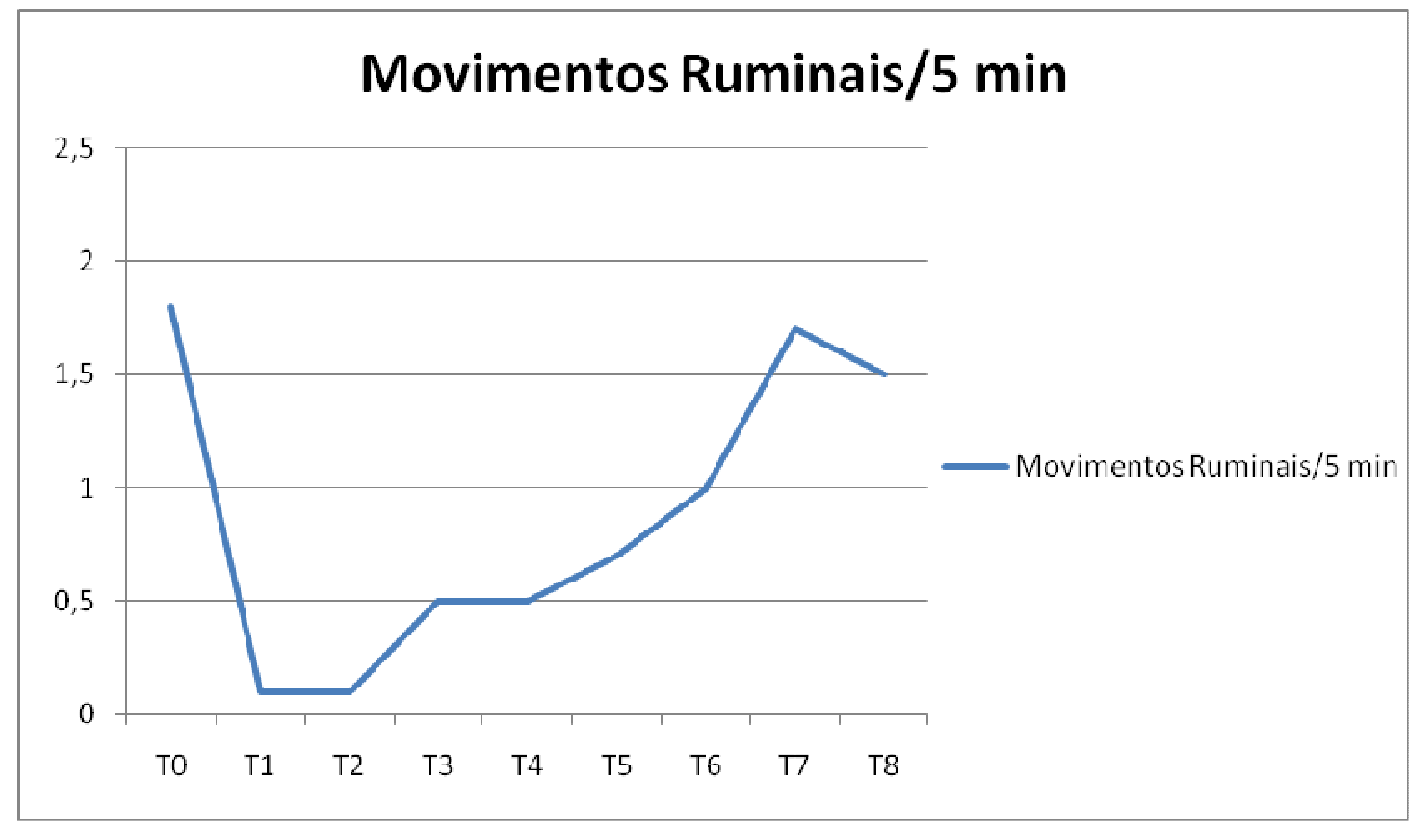

Figura 3 - Valores médios dos movimentos ruminais (em 5 min) em ovelhas tratadas com $30 \mu \mathrm{g} / \mathrm{kg}$ de cloridrato de detomidina. 


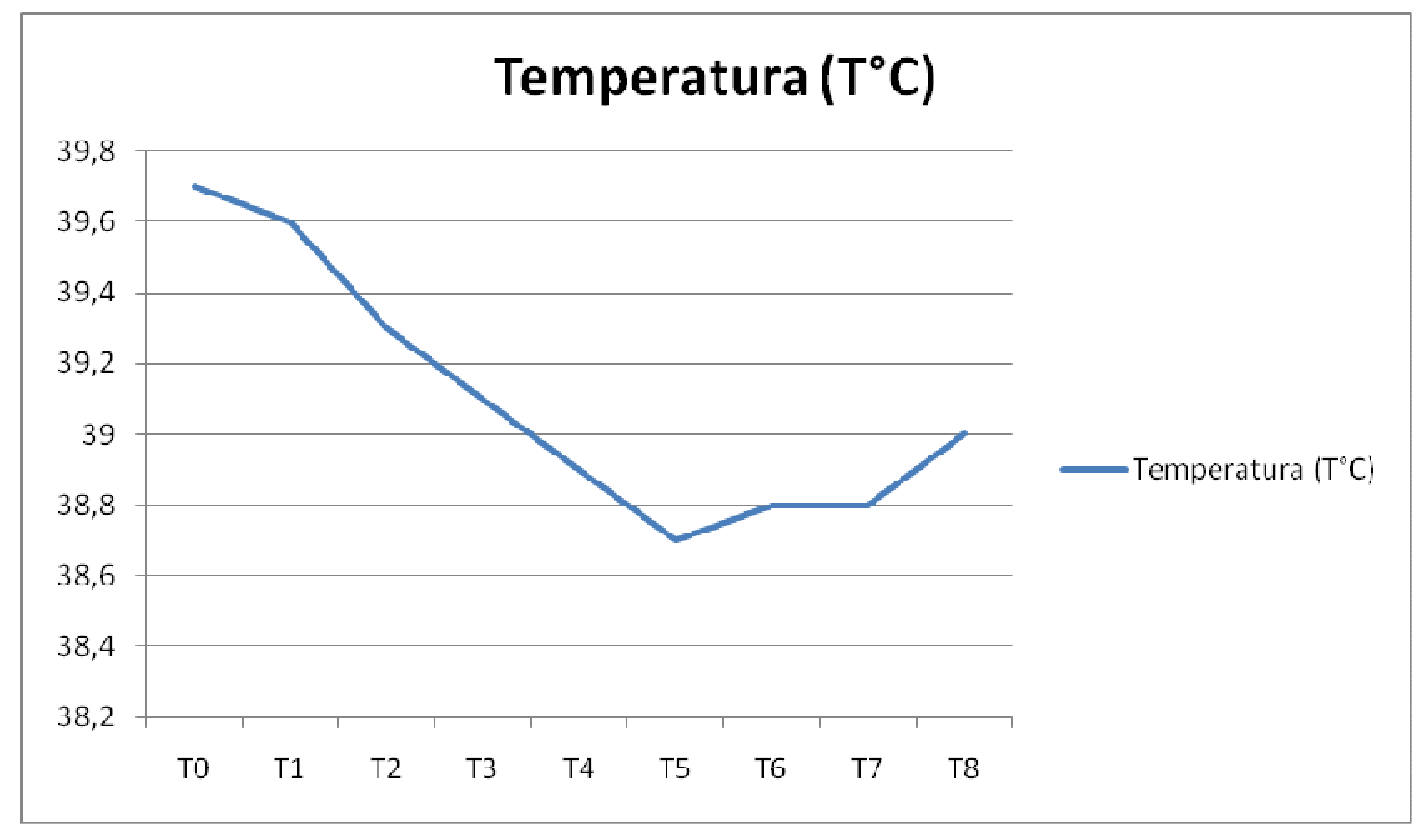

Figura 4 - Valores médios da temperatura retal $\left({ }^{\circ} \mathrm{C}\right)$ em ovelhas tratadas com $30 \mu \mathrm{g} / \mathrm{kg}$ de cloridrato de detomidina. 